\title{
THE CLASSIFICATION OF Fe IX TO XVI EMISSION LINES \\ AND ISOELECTRONIC LINES IN LABORATORY \\ AND SOLAR SPECTRA
}

\author{
B. C. FAWCETT
}

Astrophysics Research Unit, Culham Laboratory, Abingdon, Berks., England

The spectra of FeIX to XVI which dominate the XUV spectrum include the $3 p^{n}-3 p^{-1}$ $3 d$ transitions studied earlier (Fawcett et al., 1966, 1967, 1968) (Gabriel et al., 1966) and the $3 s^{2} 3 p^{n}-3 s 3 p^{n}$ transitions. A comprehensive classification of spectra from both these configurations is now completed at the Astrophysics Research Unit. The experimental method used to extend the classification of the $3 s^{2} 3 p^{n}-3 s 3 p^{n+1}$ lines in the period between potassium and vanadium was to compare the spectra of laser produced plasmas which possessed lines belonging to different ionization stages and is described by Fawcett (1970). Too many lines due to low stages of ionization obscured the $3 s^{2} 3 p^{n}-3 s 3 p^{n+1}$ lines in chromium, manganese, iron, cobalt and nickel in these

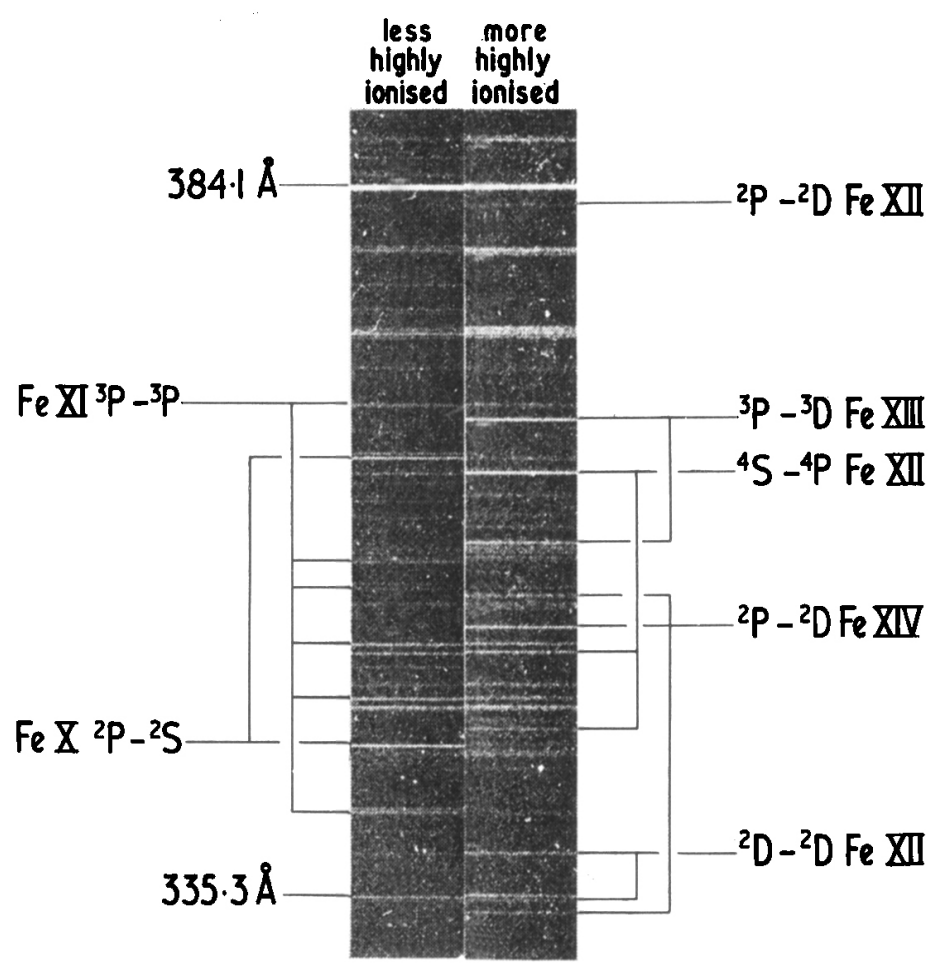

Fig. 1. Normal incidence spectra of thetatron containing iron carbonal showing $3 s^{2} 3 p^{n}-3 s 3 p^{n+1}$ emission lines of Fex to Fexiv. 
laser produced spectra for successful analysis. Volatile compounds of these elements were therefore added to the filling gas of a specially designed theta-pinch (Fawcett et al., 1971). Separation of lines of different stages of ionization was accomplished through the application of a microsecond shutter and adjusting the theta-pinch parameters. Radiation from the cooler ends of the plasma was avoided through viewing the thetapinch from the side. The illustration of $3 s^{2} 3 p^{n}-3 s 3 p^{n+1}$ emission lines of iron shows the clear separation of Fex to XI from Fexil to XIV. The new wavelengths and classifications are tabulated by (Fawcett, 1971a, b; and Fawcett and Hayes, 1971) and account for over forty new solar identifications. The data enables the calculation of the $3 s^{2} 3 p^{n}$ energy levels and hence the wavelengths of the solar forbidden lines which arise from transitions between these levels. These values confirm the identity of almost all the solar forbidden lines of iron and nickel identified by Edlén (1942) in the visible spectrum, and Gabriel et al. (1971) and Jordan (1971) in the spectra between $1000 \AA$ and $2200 \AA$ obtained during the 1970 solar eclipse with a rocket borne spectrograph. The energy levels also agree with the theoretical calculations of Svensson (1971) apart from the ${ }^{1} S$ level of Fexili.

\section{References}

Fawcett, B. C.: 1970, J. Phys. B, Atom. Molec. Phys. 3, 1732.

Fawcett, B. C.: 1971a, J. Phys. B, Atom. Molec. Phys., 4, 1577.

Fawcett, B. C.: 1971b, Astrophysics Research Unit Report ARU R3. Available from Her Majesty's Stationary Office.

Fawcett, B. C. and Hayes, R. W.: 1971, J. Phys. B. 5, 366.

Fawcett, B. C. and Gabriel, A. H.: 1966, Proc. Phys. Soc. 88, 262.

Fawcett, B. C., Gabriel, A. H., and Saunders, P. A. H.: 1967, Proc. Phys. Soc. $90,863$.

Fawcett, B. C., Peacock, N. J., and Cowan, R. D.: 1968, J. Phys. B, Atom. Molec. Phys. 1, 295. Fawcett, B. C., Gabriel, A. H., and Paget, T. M.: 1971, J. Phys. B, Atom. Molec. Phys. 4986.

Gabriel, A. H., Fawcett, B. C., and Jordan, C.: 1966, Proc. Phys. Soc. 87, 825.

Gabriel, A. H., Garton, W. R. S., Goldberg, L., Jones, T. J. L., Jordan, C., Morgan, F. J., Nicholls,

R. W., Parkinson, W., Paxton, H. J. B., Reeves, E. M., Shenjon, D. B., Speer, R. J., and Wilson, R.: 1971, Astrophys. J. 3, 545.

Jordan, C.: 1971, Solar Phys. 21, 381.

Svensson, L. A.: 1971, Solar Phys. 18, 232.

\section{DISCUSSION}

H. Nussbaumer: You observed the PxI ${ }^{1} \mathrm{D}{ }^{3} P$ intercombination line. Do you know the characteristics of your source well enough to deduce a transition probability for this line? Newer calculations of some intercombination lines differ from older ones by more than a factor 2; experimental data would therefore be desirable.

B. C. Fawcett: The theta-pinch light source was designed for such studies which require a knowledge of the parameters of the plasma. Furthermore the thetapinch is equipped with laser scattering diagnostics and hence the parameters of the plasma can be determined as a function of time. Provided such technical difficulties, such as the determination of the number density of the ions studied, are overcome then the absolute intensity of any line reported in the thetapinch spectra can be measured. The interpretation of these intensities then becomes a problem for the theoretician. 